\title{
Debate sobre la historia que se enseña en España ${ }^{1}$ Ramón López Facal \\ Instituto de Enseñanza Secundaria de Pontepedriña, A. Coruña
}

Nacionalismo historiográfico y mercantilización de la enseñanza

El franquismo trató de imponer una versión exacerbada de nacionalismo casticista plagada de obsesiones católico-integristas. Pretendió liquidar cualquier vestigio de otros nacionalismos alternativos. Al vincular la idea de nación a valores premodernos, abiertamente enfrentados a la idea de progreso, contribuyó a que ésta entrase en crisis tan pronto como se inició, en los años sesenta, un proceso de modernización de la sociedad española y acabó por favorecer, paradójicamente, a esos otros nacionalismos que adquirieron mayor legitimidad social, al ser asociados a ideologías democráticas y mode-rnizadoras en tanto que antifranquistas.

El final de la dictadura franquista fue seguido por un inmediato y generalizado rechazo popular a sus símbolos. Se cuestionaron los valores excluyentes que había tratado de inculcar por la fuerza. El deseo de superar cuanto antes el régimen que acababa de desaparecer facilitó el abandono de las ideas en las que se había sustentado el nacionalismo español desde sus orígenes, tanto los mitos fundacionales de la nación (Sagunto, Viriato, Don Pelayo) como su misma concepción centralista y uniformizadora. Al mismo tiempo, adquirieron legitimidad democrática ideas y prácticas alternativas al viejo nacionalismo centralista español, lo que puede explicar, en parte, la casi nula oposición popular a la profunda transformación política y administrativa del estado que significó la nueva estructura autonómica.

Los nuevos ámbitos de poder nacidos con la transición democrática se apresuraron a crear los elementos simbólicos que legitimasen su existencia, recurriendo de nuevo al descubrimiento de las esencias regionales o nacionales a través de elementos historicistas y organicistas. En pocos años, todas las Comunidades autónomas se han dotado de sus correspondientes historias y geografías que demuestran su unidad orgánica en el tiempo y el espacio. Resulta significativo que se hayan reeditado, incluso, las historias románticas del siglo XIX, al menos en el caso de Galicia y Valencia, siendo completadas hasta el momento presente -como antaño- a cargo de historiadores actuales.

La nación es una idea, un sentimiento, no una realidad material; es una construcción político-ideológica que se ha desarrollado durante el siglo XIX tratando de garantizar la cohesión social de una colectividad a partir de la creencia en una identidad compartida. 
La pervivencia de concepciones esencialistas, vergonzantemente ocultadas por los viejos nacionalismos europeos, se manifiesta sin complejos en aquellos otros que les son alternativos y que, en el caso español, se revisten además de legitimidad democrática por su pasado antifranquista. El resultado es la afirmación de una España mucho más plurinacional de lo que había sido en el pasado. La construcción del llamado Estado de las autonomías durante la transición democrática ha contribuido, por una parte, a deslegitimar la variante casticista, centralista y autoritaria del nacionalismo español que ha evolucionado hacia posiciones democráticas, europeístas y autonomistas y, a la vez, ha reforzado la identidad de los nacionalismos subestatales. El resultado, con la trágica excepción del País Vasco, ha sido permitir satisfacer bastantes aspiraciones nacionalistas limitando las posiciones independentistas. Pero, como señala Beramendi (2002), al tiempo que situaba el pleito nacional en una baja cota de conflictividad, lo ha estabilizado, convirtiendo las relaciones entre las entidades subestatales y el Estado en un contencioso permanente.

En estas circunstancias nace la sensación de crisis y malestar creciente entre los nacionalistas españoles que consideran haber hecho un esfuerzo notable, incluso excesivo, a favor de sus competidores. Se sienten huérfanos, además, de las únicas referencias nacionales que han conocido y en las que se han formado (la historia común, el territorio común, el carácter común... de los españoles), cuestionados por quienes tienen un referente nacional alternativo que se basa en la permanente reivindicación de una comunidad diferente.

Los nacionalistas españoles viven con desazón la crisis de la idea de España que no es unánimemente aceptada -nunca lo ha sido-, pero que ahora además se cuestiona no sólo por los nacionalismos históricos sino incluso por los neoautonomismos surgidos a partir de la nueva estructura del Estado. A esto cabe añadir el desasosiego ante el creciente flujo inmigratorio visto como una amenaza para la supervivencia de una identidad cultural que consideran consustancial a su idea de nación. Como reacción, tratan de imponer el regreso a las viejas esencias nacionales asociadas a la función nacionalizadora de la historia. ${ }^{2}$ No comprenden que lo que está en crisis no es la historia de España, sino un cierto sentimiento de la nación española nacido en unas circunstancias muy diferentes.

Los intentos de sustentar el nuevo nacionalismo español en un discurso más pluralista e integrador tal como parece pretender la ponencia del último congreso del PP sobre Patriotismo Constitucional ${ }^{3}$-que, salvo en el nombre, poco tiene que ver con el discurso de Sternberger o Habermas- no logran superar viejos estereotipos. Se sacraliza el texto constitucional hasta considerarlo prácticamente inmutable, ya que lo califican como el único adecuado a los "rasgos esenciales" de la nación española ("el modelo del Estado Autonómico en el proceso constituyente se debe a que es el que mejor se adapta a los rasgos esenciales de la España plural"), y se mantiene el viejo discurso historicista como fuente de legitimidad ("España es una nación política forjada a lo largo de una 
dilatada trayectoria histórica...").

En la actualidad se ha generalizado un sentimiento de crisis de la enseñanza que no se circunscribe a los contenidos de historia. Los poderes económicos, desde la OCDE ${ }^{4}$ a los grandes grupos financieros, prevén un nuevo marco educativo en el que predominará la mercantilización de la enseñanza. Tienden a considerar un despilfarro el destino de recursos públicos para una formación de la mayoría de la población, puesto que la consideran innecesaria en una sociedad en la que el número de personas técnicamente cualificadas va a ser muy reducido a causa de la automatización de los procesos productivos; la perspectiva de crecimiento del empleo se concentra fundamentalmente en trabajos de escasa cualificación como limpiadores, servicios de seguridad privada, mensajeros y distribuidores de mercancías, etc. En este contexto, quizá se entienda mejor la coincidencia de voces e intereses que se manifiestan contra la "degradación" de la enseñanza pública, al tiempo que ocultan la reducción del porcentaje de PIB destinado a su mantenimiento.

Las políticas educativas neoconservadoras claman por conseguir una formación eficiente y competitiva, orientada al mercado. La obsesión por la introducción de ordenadores, por poner un ejemplo, se centra más en la familiarización de los futuros trabajadores con las máquinas que en los contenidos que propicien el desarrollo personal de sus capacidades cognitivas. Pero, al mismo tiempo, existe la preocupación por garantizar la cohesión social en torno de un sistema político. Y en una sociedad plural como la española, con varios referentes nacionales en competencia, se vuelven los ojos a la enseñanza de la historia y de la lengua, e incluso de la religión, en la creencia de que con ello sería posible, como en el pasado, garantizar la cohesión en una sociedad marcadamente desigual y, al tiempo, neutralizar a los "otros" nacionalismos contrincantes. Pero a pesar del notable incremento de los contenidos escolares en estas materias, las opciones nacionales de la población no parecen modificarse. Esto refuerza la percepción de fracaso del sistema escolar, incapaz de cumplir la misión imposible que pretende encomendársele desde el poder.

La historia nacional en crisis

El sentimiento de crisis de la enseñanza de la historia surge desde la añoranza de aquellos que evocan la intencionalidad patriótica de los manuales escolares de su infancia, llenos de referencias míticas, actualmente ausentes en los programas y en los libros de texto, a la que nos hemos referido antes.

El viejo concepto de nación resulta poco compatible con las sociedades democráticas, cada vez más mestizas, y la enseñanza de la historia se ha orientado progresivamente, en las enseñanzas no universitarias, hacia la interpretación de una identidad supranacional. El fracaso relativo del nacionalismo español ha facilitado un mayor desarrollo de nacionalismos con un referente alternativo (catalán, gallego, vasco...) aunque 
tampoco éstos hayan logrado la derrota, eliminación o superación del sentimiento nacional español en sus respectivos territorios. Nos encontramos en este momento con un "empate histórico" entre el nacionalismo español y los periféricos, "cuando no con la constatación de un doble y paradójico fracaso" (Núñez Seixas, 1999) en que ambos se bloquean mutuamente ante la imposibilidad de implantarse uno de ellos de manera exclusiva o hegemónica.

Las sucesivas encuestas del CIS coinciden todas ellas en mostrar que la mayoría de la población de las comunidades en las que la presencia de nacionalismos alternativos al español es muy relevante, asume como compatible la doble identidad, española y autonómica. ${ }^{5}$ Esta situación no es necesariamente estable o permanente, y puede cambiar por motivos variados (cualquier crisis institucional, económica, etc., puede tener efectos imprevisibles).

La importancia que se atribuye a la historia en los imaginarios nacionalistas (español o alternativos) hace que los contenidos de esta asignatura y su orientación sean un permanente campo de confrontación ideológica, lo que no sucede con otras materias: resultaría insólito que un ministro discrepase de un consejero autonómico sobre la enseñanza de la física, las matemáticas o, incluso, sobre los contenidos de lengua y literatura en las que también existe un obvio componente ideológico. Pero parecen normales (por lo frecuentes) las polémicas sobre la enseñanza de las humanidades, que en la práctica se limitan a reclamar la presencia de un "legado histórico común" por parte de unos, frente a otros que reivindican el conocimiento de sus "raíces específicas". El error está en seguir concibiendo hoy la enseñanza en general, y la de la historia en particular, como el instrumento para la formación de una identidad nacional. Suele ignorarse que en las clases de historia y ciencias sociales no es en donde se transmiten hoy más mitos nacionalistas; tienen mucha más presencia en materias como Lengua y Literatura y, sobre todo, en los medios de comunicación y en los demás ámbitos que conforman las representaciones sociales (el pensamiento común) de la población.

\section{Contrarreforma escolar y enseñanza de la historia}

En una valoración, quizá algo optimista, Carlos Forcadell (1998) afirma que, desde lo que él denomina la comunidad profesional, "nadie parece contradecir que no hay que formar alumnos educados (nacionalmente), sino ciudadanos educados para la crítica, el ejercicio de la libertad personal e intelectual, y las movedizas exigencias de la aldea global". Tal vez su afirmación sea genéricamente cierta si se refiere exclusivamente a la investigación académica, pero no pocos de esos mismos investigadores, incluso prestigiosos, defienden la necesidad de renacionalizar y ampliar los contenidos de historia de España en las enseñanzas medias desde una perspectiva que como mínimo habría que calificar de arcaica. Cabría deducir de esta posición que sólo consideran necesario el rigor histórico para la formación universitaria, mientras que para la mayoría 
de la población la principal finalidad de la historia debe seguir siendo, en su opinión, la transmisión de los mitos nacionalistas. Estas perspectivas se han impuesto con las últimas reformas, o contrarreformas educativas, que cuentan para ello además con el consenso social que le proporciona el acriticismo, basado en el sentido común, de una sociedad que apenas acaba de salir de alarmantes tasas de analfabetismo y que en su conjunto cuenta con un notable déficit cultural.

Al arcaísmo historiográfico de los reformados currículos de las enseñanzas secundarias, se suma el metodológico y pedagógico. Los procesos de enseñanza-aprendizaje se entienden como un simple acto de transmisión de contenidos (emisión-recepción); consecuentemente, en los nuevos programas se incrementa notablemente la cantidad de "transmisiones" previstas, tanto en horas lectivas (una más a la semana en algún curso) como, sobre todo, muchos más contenidos. Si "más" equivale a "mejor", hay que multiplicar los temas para abarcar "toda" (sic) la historia de España. Un profesor de secundaria dispone de menos de dos sesiones de clase para ocuparse de cada uno de los sesenta y cinco enunciados del $2^{\circ}$ curso de bachillerato (o del primero de la ESO) presentes en los nuevos programas de Galicia (muy similares, por lo demás, a los de otras comunidades). ${ }^{6}$ Si desea atenerse a los objetivos y criterios de evaluación que se le señalan, debe lograr en apenas 90 minutos que el alumnado se familiarice con fuentes, valore críticamente los procesos, establezca relaciones temporales y territoriales, y un largo etcétera, sobre temas de la complejidad de "Hispania Romana. Gallaecia: El proceso de romanización. Especial atención al caso gallego"; "El feudalismo. Economía y sociedad"; "El imperio de Carlos V y la Monarquía Hispánica de Felipe II”; “El sistema de Westfalia-Pirineos: Ocaso de la hegemonía de los Habsburgo. Crisis interna"; "Las Cortes de Cádiz y la Constitución de 1812" o "La transición política. La Constitución de 1978 y el Estado de las Autonomías"; por sólo citar algunos ejemplos.

Otra cultura escolar para una sociedad diferente

Los profundos cambios experimentados en las sociedades actuales -entre otros, los que afectaron a las comunicaciones y difusión de la información- hacen que una enseñanza que se base en la transmisión de informaciones sea estéril. En la actualidad, cualquier adolescente tiene a su disposición una enorme avalancha de informaciones sobre casi cualquier tema entre los que se incluyen, por supuesto, los históricos pero, al mismo tiempo, carece de los más elementales criterios para poder seleccionar, jerarquizar, estructurar y valorar todo aquello que recibe. Ninguna escuela puede competir, ni en medios ni en tiempo o intensidad, con las fuentes de información extraescolares (cine, cómics, televisión). La función de la enseñanza no puede por ello seguir siendo la de transmitir más informaciones, como cuando no existía esa amplia difusión masiva, sino la de contribuir a que los y las estudiantes sean capaces de analizar críticamente 
las informaciones que se les ofrecen y elaborar juicios de valor razonados sobre los aspectos de la convivencia humana que la sociedad, en cada momento, considera más problemáticos o relevantes. Esa capacidad de análisis crítico implica una dimensión temporal, histórica, ya que es necesario comprender la génesis y evolución de aquello que nos preocupa para poder alcanzar un conocimiento más riguroso del presente. Con estas premisas, la enseñanza de la historia no puede tratar de abarcar contenidos excesivamente amplios -y mucho menos en la adolescencia- sino, por el contrario, delimitar los contenidos sobre los que se trabaje en el aula. La amplitud de los contenidos escolares conduce en menor o mayor medida a caer en la superficialidad y la simplificación, es decir, lo contrario a desarrollar capacidades críticas.

La cultura occidental ha estado presidida desde el siglo XVIII por la idea de que la humanidad disfrutaba de un progreso continuado gracias al desarrollo científico y técnico; su misión era someter a las fuerzas irracionales de la naturaleza y erradicar la ignorancia y la barbarie. La historia servía para documentar el progreso hacia la civilización representada por los estados nacionales que garantizaban la estabilidad, el orden, el crecimiento económico y el desarrollo cultural, y alcanzaban su culminación en el expansionismo colonialista. Estos tópicos culturales, que responden a una mentalidad burguesa, ${ }^{7}$ hace tiempo que han sido cuestionados, pero siguen integrando las representaciones sociales asumidas por un elevado número de personas. Si no existe una reflexión crítica, fundamentada en conocimientos, los estereotipos son muy difíciles de superar.

La extensión de la educación a toda la población hasta los 16 años es un hecho muy reciente; la mayoría de los y las escolares que finalizan la ESO representa la primera generación que alcanza ese nivel de escolarización en sus respectivas familias. Paradójicamente, existe la percepción de que los adolescentes aprenden y saben menos que antes. Las causas de esta distorsión son complejas. En la actualidad, la mayoría de los jóvenes aprende muchas más cosas que antes, pero la mayoría de ellas es diferente de las que a esa edad se aprendían hace treinta o cuarenta años; en todo caso, lo que aprenden es mucho menos de lo que pretenden sus profesores, sus padres o la administración. Las demandas crecientes de aprendizaje desbordan ampliamente las posibilidades de cualquier sistema escolar, con lo que se produce el efecto paradójico de deterioro: parece que cada vez se aprende menos porque cada vez se exige conocer más cosas y más complejas. Es necesario asumir seriamente un cambio cultural en la enseñanza. No se puede seguir utilizando estrategias educativas del siglo XIX, por parte de profesores del siglo XX, para responder a las nuevas demandas sociales del siglo XXI.

A favor de una nueva enseñanza de la historia

Pero el problema no se limita a las estrategias educativas, sino también a los conte- 
nidos "canónicos" de la historia escolar, que ha heredado las viejas estructuras y orientaciones de la cultura burguesa decimonónica. La formación histórica puede contribuir a desarrollar capacidades críticas pero no a partir de cualquier selección de contenidos. La historia enseñada sigue siendo fundamentalmente eurocéntrica, con una estructura cronológica justificada teleológicamente, nacionalista, androcéntrica... Existe un sentimiento de crisis de estos caducos patrones que provoca desasosiego entre quienes siguen asumiendo íntimamente la historia como una justificación del orden presente y manifiestan su rechazo ante las escasas y tímidas propuestas reformistas de contemplar nuevos planteamientos, exigiendo la buena y vieja historia de siempre. No es habitual que desde ámbitos de poder, académico o político, se cuestionen abiertamente los nuevos valores sociales emergentes, pero que en la práctica se rechacen al excluirlos de la reflexión histórica o del currículo escolar.

Es necesario cuestionarse si los contenidos presentes en los currículos actuales son los adecuados para formar ciudadanos críticos capaces de construir una sociedad más democrática y solidaria. O si la educación histórica debiera ocuparse preferentemente de analizar la génesis y evolución de los grandes problemas presentes en nuestra época: los que afectan a la vida de las personas, los recursos y la subsistencia de los seres humanos; a sus formas de organización social, tanto del ámbito familiar como las relaciones de género y clase y, por supuesto, las que se refieren a la convivencia política; las relaciones de poder y dominación; las creencias, conocimientos, formas culturales y artísticas; las razones por las que amplios colectivos han estado excluidos de la historia oficial, etc., que reflejan y condicionan la percepción del mundo. $Y$ al tiempo que nos planteamos el qué: los nuevos contenidos acordes con las finalidades y valores que deseamos desarrollar en nuestra sociedad, superando los mitos nacionalistas del pasado, es necesario revisar también el cómo: si las estrategias tradicionales son las adecuadas para que la mayoría de la población consiga pensar históricamente sobre lo que la rodea.

Los que entendemos la educación como una vía para la emancipación intelectual y personal que haga posible que cada persona conozca y entienda el mundo en el que le ha tocado vivir y pueda imaginar y desear otro mejor, consideramos que el papel de la historia en la educación obligatoria y en los bachilleratos debe superar rutinas y tradiciones seculares y planteamientos corporativistas. Su presencia en el currículo escolar sólo puede justificarse, desde este punto de vista, por su capacidad formativa al proporcionar explicaciones sobre la génesis de la sociedad actual: sus conflictos y desigualdades, sus logros y realidades; nunca por sí misma (con mentalidad de anticuario), "por tradición". La parcelación de conocimientos propios de la investigación académica y el establecimiento de áreas que responden con frecuencia más a intereses corporativos que funcionales, no pueden trasladarse mecánicamente a la enseñanza obligatoria donde la división entre geografía, historia o economía pierde sentido cuando se trata de facilitar la comprensión de los mecanismos por los que nuestra sociedad ha llegado a ser lo que es hoy, y por qué es de ésta y no de otra manera. Esa explicación 
no puede satisfacerse desde una sola área, sino que es tan compleja como la sociedad misma y ninguna ciencia social, en exclusiva, posee las claves explicativas del devenir histórico.

Pero de todas ellas, la historia, antes como ajuste de cuentas que como exaltación del pasado, permite indagar en las raíces de los problemas que hoy más nos preocupan. Ésa es su principal dimensión educativa. Aprender de los errores ya cometidos. Afirman J. A. Marina y María de la Válgoma (2000) que "el elogio del pasado es una astucia de aspirantes a privilegiados", que podemos reformular afirmando que la crítica rigurosa del pasado previene contra el engaño de quienes pretenden perpetuar sus privilegios. Para ello es necesario tratar de comprender en cada momento los conflictos que más nos afecten.

Notas

${ }^{1}$ Los argumentos que se plantean a continuación los he desarrollado más ampliamente en la ponencia "Enseñar la historia de la gente" expuesta en el Institut d'Estudis Històrics Jaume Vicens Vives de la U. Pompeu Fabra (Barcelona, 25-26 de junio de 2002, en prensa).

${ }^{2}$ Esta crisis del sentimiento nacional no existe sólo en España. El diputado conservador británico John Stokes se expresaba así en una sesión parlamentaria, en 1990: “En la actualidad existe una gran preocupación sobre la enseñanza de la Historia en nuestras escuelas. En vez de enseñar generalidades y grandes temas, ¿por qué no se vuelve a los buenos tiempos de antaño en que se aprendía de memoria los nombres de reyes y reinas de Inglaterra, batallas, hechos y todos los gloriosos acontecimientos de nuestro pasado?" [Citado por Pilar Maestro, 1996].

${ }^{3}$ Texto disponible en http://www.pp.es -durante el mes de diciembre de 2001.

${ }^{4}$ Ver, por ejemplo, Morrison, Christian: “La Faisabilité politique de I'ajustement", Centro de desarrollo de la OCDE, Cuaderno de política económica, número 13, 1996. [Citado por Nico Hirtt].

5 "Fenómeno general, adquiere su dimensión más significativa en las nacionalidades históricas, donde se ha desarrollado una doble identificación que no entiende ambas dimensiones como excluyentes, sino como complementarias o - aún más visualmente- como concéntricas" (Se- 
púlveda, 1996:443).

${ }^{6}$ http://www.xunta.es/conselle/ceoug/dxoefp/index.htm

7 "Por burgués no entendemos aquí, en el sentido de Marx, una clase definida ante todo por su relación con los medios de producción, sino un mundo vital, un modo de pensar y de actuar, que si bien está relacionado con las circunstancias de poder político y económico, las excede con mucho e influye en ellas" (Iggers, 1998, p. 18).

\section{Bibliografía}

Beramendi, J. G. (2002): "Identidad, etnicidad y estado en España. Siglos XIX y XX" en Safran, W. y Maiz R. (coord.): Identidad y autogobierno en sociedades multiculturales, Ariel, Barcelona.

Forcadell Álvarez, C. (1998): "Historiografía española e Historia nacional: la caída de los mitos nacionalistas" en Ayer, nro. 30.

Hirtt, N. (2001): "Les trois axes de la marchandisation escolaire" en Etudes Marxistes, nro. 56.

Iggers, G. (1998): La ciencia histórica en el siglo XX, Idea Books, Barcelona. Maestro, P. (1996): Historiografía y enseñanza de la historia, Tesis doctoral (inédita), Universidad de Alicante.

Marina, J. A. y Válgoma, M. (2000): La lucha por la dignidad, Anagrama, Barcelona.

Núñez Seixas, X. M. (1999): Los nacionalismos en la España contemporánea (siglos XIX y XX), Hipòtesi, Barcelona.

Sepúlveda, I. (1996): “La eclosión nacionalista: regionalismos, nacionalidades y autonomías" en Tusell, J. U. y Soto A. (ed.): Historia de la transición, Alianza, Madrid. 